Buletin Ilmiah Math. Stat. dan Terapannya (Bimaster)

Volume 08, No. 4 (2019), hal 783 - 788.

\title{
ESTIMASI PARAMETER MODEL INTEGER-VALUED AUTOREGRESSIVE ORDE SATU (INAR(1))
}

\author{
Aloysius Billy Saga, Yundari, Shantika Martha
}

\begin{abstract}
INTISARI
Model Integer-value autoregressive orde satu (INAR(1)) adalah salah satu model yang digunakan untuk memodelkan data deret waktu berupa bilangan cacah. Berdasarkan asumsi kestasioneran lemah dari data deret waktu maka sifat-sifat statistik yang dibahas adalah rata-rata dan variansi. Dalam model INAR(1) terdapat parameter yang belum diketahui dan perlu diestimasi yaitu probabilitas bertahan dalam suatu proses $(\alpha)$ dan parameter komponen kedatangan ( $\lambda$ ). Pada penelitian ini parameter $\alpha$ diestimasi menggunakan metode Yule-Walker dan kuadrat terkecil bersyarat sedangkan parameter $\lambda$ diestimasi menggunakan metode maksimum likelihood dan kuadrat terkecil bersyarat. Hasil yang diperoleh adalah rata-rata dari model INAR(1) adalah $E\left[X_{t}\right]=\frac{\mu}{1-\alpha}$ dan variansinya $\operatorname{var}\left(X_{t}\right)=\frac{\alpha \mu+\sigma^{2}}{1-\alpha^{2}}$, sedangkan hasil estimasi parameter yang diperoleh adalah estimasi parameter $\hat{\alpha}=\frac{\sum_{t=0}^{n-1}\left(x_{t}-\bar{x}\right)\left(x_{t+1}-\bar{x}\right)}{\sum_{t=0}^{n}\left(x_{t}-\bar{x}\right)^{2}}$ dan $\hat{\lambda}=\frac{1}{n} \sum_{t=1}^{n} \varepsilon_{t}$.
\end{abstract}

Kata Kunci: Yule-Walker, Maksimum Likelihood, Kuadrat Terkecil Bersyarat.

\section{PENDAHULUAN}

Data berbentuk bilangan cacah merupakan data deret waktu diskrit[1]. Data berbentuk bilangan cacah adalah data yang dihitung sebagai jumlah kejadian dalam interval waktu atau dalam interval ruang. Misalnya data banyaknya titik api yang terjadi di wilayah Pontianak dalam setiap bulan, banyaknya orang yang meninggal akibat penyakit jantung dalam setiap bulan, dan banyaknya orang meninggal akibat kecelakaan dalam setiap bulan. Distribusi yang digunakan untuk mewakili distribusi data berbentuk bilangan cacah adalah Poisson, binomial, dan negatif binomial[2]. Salah satu model yang digunakan untuk data berbentuk bilangan cacah adalah Integer-value Autoregressive (INAR). Model INAR terdiri dari dua komponen yaitu survivors dalam proses sebelumnya dan kedatangan[1]. Dalam model INAR terdapat parameter yang belum diketahui dan perlu diestimasi yaitu probabilitas bertahan dalam suatu proses $(\alpha)$ dan parameter kedatangan $(\lambda)$.

Metode estimasi parameter untuk INAR(1) ada berbagai macam, seperti metode momen atau Yulewalker, maksimum likelihood, kuadrat terkecil bersyarat, dan Bayesian. Pada penelitian ini dikaji ulang metode Yule-walker, maksimum likelihood, dan kudrat terkecil bersyarat untuk mengestimasi parameter model INAR(1). Metode tersebut hanya efektif untuk model dengan orde rendah, sedangkan untuk orde yang lebih tinggi digunakan metode lainnya. Rumusan masalah yang dibahas dalam penelitian ini adalah bagaimana sifat- sifat model INAR(1) dan bagaimana cara megestimasi parameter INAR(1).

Permasalahan yang dibahas pada penelitian ini hanya untuk INAR(1) dengan waktu kedatangan berdistribusi Poisson, sehingga berlaku untuk himpunan variabel acak diskrit (ruang keadaan). Digunakan asumsi stasioner lemah (orde 2) pada data deret waktu. Penelitian ini membahas beberapa metode dalam mengestimasi parameter yang terdapat dalam model INAR(1)[3]. Penelitian dimulai dengan mempelajari model AR(1) dan sifat-sifat statistiknya dilanjutkan dengan mempelajari model INAR(1) dan mencari sifat-sifat statistiknya kemudian mengestimasi parameternya. Model INAR(1) berbeda dengan model AR(1) karena memiliki dua variabel acak yang independen. Model INAR(1) merupakan pengembangan dari model AR(1) sehingga dibahas pula sifat-sifat statistik dari model $\operatorname{INAR}(1)$. 


\section{PROSES STOKASTIK}

Proses stokastik adalah himpunan variabel acak $\left\{X_{t}, t \in T\right\}[4]$. Semua kemungkinan nilai yang dapat terjadi pada variabel acak $X_{t}$ disebut ruang keadaan dan satu nilai t dari T disebut indeks atau parameter waktu. Dengan parameter waktu ini, proses stokastik dapat dibedakan menjadi dua bentuk yaitu proses stokastik berparameter diskrit contohnya banyaknya barang terjual di sebuah toko per hari dan proses stokastik berparameter kontinu contohnya volume air di sebuah bendungan pada waktu sebarang.

Proses stokastik terdapat dua jenis kestasioneran yang dikenal, yaitu stasioner kuat dan stasioner lemah. Suatu proses dikatakan stasioner kuat jika distribusinya tidak dipengaruhi waktu (invarian terhadap waktu). Artinya, setiap momen dari proses tersebut harus invarian terhadap waktu. Jika yang invarian hanya momen pertama (rataan) dan momen kedua (variansi/kovariansi), maka kestasioneran tersebut dinamakan stasioner lemah. Namun demikian, jika proses tersebut diasumsikan berdistibusi identik, normal, maka stasioner lemah akan identik dengan stasioner kuat[5].

\section{DISTRIBUSI POISSON}

Distribusi Poisson adalah distribusi nilai-nilai bagi suatu variabel acak X (X diskrit), yaitu banyaknya hasil percobaan yang terjadi dalam suatu interval waktu tertentu atau disuatu daerah tertentu [6]. Distribusi Poisson termasuk distribusi teoritis yang memakai variabel acak diskrit. Fungsi peluang dari distribusi Poisson adalah

$$
p(x)=\frac{\lambda^{x} e^{-\lambda}}{x !}
$$

dengan $\lambda=$ parameter distribusi Poisson, $p=$ probabilitas sukses, $x=$ variabel acak diskrit.

\section{DERET WAKTU}

Deret waktu adalah rangkaian data yang berupa nilai pengamatan yang diukur selama kurun waktu tertentu dengan interval yang sama [7]. Analisis deret waktu adalah suatu analisis terhadap pengamatan, pencatatan dan penyusunan peristiwa yang diambil dari waktu kewaktu tersebut [8]. Analisis data deret waktu dapat digunakan untuk membuat keputusan pada jangka waktu yang panjang berdasarkan data masa lalu dan data sekarang. Dalam menentukan keputusan, diperlukan prediksi kejadian yang terjadi di masa mendatang, sehingga dapat mengantisipasi kemungkinan terjadi hal-hal tidak diinginkan yang akan menimbulkan kerugian ataupun risiko. Sebagai contohnya banyaknya gol dalam suatu pertandingan dari 2001-2018 dan jumlah penduduk di suatu tempat pada kurun waktu tertentu. Beberapa sifat statistik dari model deret waktu yang perlu dikaji adalah rata-rata dan kovariansi.

Kovariansi adalah suatu ukuran yang menyatakan variansi bersama dari dua variabel acak [9]. Misalkan $\left\{X_{t}\right\}$ adalah suatu deret waktu dengan $E\left(X_{t}^{2}\right)<\infty$. Fungsi rata-rata deret $X_{t}$ adalah

Sedangkan fungsi kovariansinya adalah

$$
\mu_{X}(t)=E\left[X_{t}\right]
$$

$$
\begin{aligned}
\gamma_{X}(r, s) & =\operatorname{cov}\left(X_{r}, X_{s}\right) \\
& =E\left[\left(X_{r}-\mu_{X}(r)\right)\left(X_{s}-\mu_{X}(s)\right)\right]
\end{aligned}
$$

untuk semua bilangan bulat $\mathrm{t}, \mathrm{r}$, dan $\mathrm{s}$.

\section{PROSES AUTOREGRESI}

Salah satu proses stokastik dengan ruang keadaan diskrit dan waktu diskrit adalah analisis deret waktu. Model analisis deret waktu yang terkenal adalah model autoregresi (AR). Proses autoregresi tingkat ke-p dari deret waktu $\left\{X_{t}\right\}$, disingkat $\operatorname{AR}(\mathrm{p})$, memenuhi persamaan

$$
X_{t}=\phi_{1} X_{t-1}+\phi_{2} X_{t-2}+\cdots+\phi_{p} X_{t-p}+\varepsilon_{t}
$$


Dengan asumsi $\varepsilon_{t}$ i.i.d. $\mathrm{N}\left(0, \sigma^{2}\right)$ saling bebas dengan $X_{t-1}, X_{t-2}, \ldots$. Untuk orde 1 ditulis AR(1), maka modelnya sebagai berikut

$$
X_{t}=\phi_{1} X_{t-1}+\varepsilon_{t}
$$

Sifat-sifat statistik dari model AR(1) adalah rata rata dan kovariansi. Menggunakan persamaan rataratanya didapat $\mu_{t}=0$ atau $1-\phi_{1}=0$ karena $X_{t}$ stasioner maka $E\left[X_{t}\right]=\mu_{t}=0$

Sedangkan variansinya diperoleh

$$
\begin{aligned}
\operatorname{var}\left(X_{t}\right) & =\operatorname{var}\left(\phi_{1} X_{t-1}+\varepsilon_{t}\right) \\
\operatorname{var}\left(X_{t}\right)-\phi_{1}^{2} \operatorname{var}\left(X_{t-1}\right) & =\operatorname{var}\left(\varepsilon_{t}\right) \\
\gamma_{0}-\phi_{1}^{2} \gamma_{0} & =\sigma^{2} \\
\left(1-\phi_{1}^{2}\right) \gamma_{0} & =\sigma^{2} \\
\gamma_{0} & =\frac{\sigma^{2}}{1-\phi_{1}^{2}}
\end{aligned}
$$

Adapun untuk kovariansi dari model AR(1) adalah

$$
\begin{aligned}
\operatorname{cov}\left(X_{t}, X_{t-k}\right) & =\phi_{1} E\left[X_{t-1} X_{t-1}\right]+E\left[\varepsilon_{t} X_{t-1}\right] \\
\gamma_{k} & =\phi_{1} \gamma_{k-1}
\end{aligned}
$$

misalkan untuk $\mathrm{k}=1$ maka diperoleh

$$
\gamma_{1}=\phi_{1} \gamma_{0}=\phi_{1} \frac{\sigma^{2}}{1-\phi_{1}^{2}}
$$

untuk k=2 maka diperoleh

$$
\gamma_{2}=\phi_{1} \gamma_{1}=\phi_{1} \phi_{1} \frac{\sigma^{2}}{1-\phi_{1}^{2}}=\phi_{1}^{2} \frac{\sigma^{2}}{1-\phi_{1}^{2}}
$$

sehingga secara umum diperoleh

\section{METODE YULE-WALKER}

$$
\begin{aligned}
& \gamma_{k}=\phi_{1}^{k} \gamma_{0} \\
& \frac{\gamma_{k}}{\gamma_{0}}=\phi_{1}^{k}=\rho_{k} .
\end{aligned}
$$

Estimasi parameter model AR dengan metode Yule-Walker adalah estimasi dengan mensubstitusi momen sampel, diantaranya yaitu rata-rata sampel dan fungsi autokorelasi sampel. Untuk parameter $\mu$ diperoleh dengan menyamakan momen sampel ke-1 dan momen populasi ke-1yaitu $E\left[X_{t}\right]=\hat{\mu}$ diestimasi dengan

$$
\frac{1}{n} \sum_{t=1}^{n} X_{t}=\bar{X}
$$

sehingga didapat estimasi rata-rata adalah $\mu=\bar{X}$

Untuk memperoleh estimasi dari $\phi_{1}, \phi_{2} \ldots, \phi_{p}$, pertama persamaan AR(p) dikalikan dengan $\tilde{X}_{t-h}$ yaitu:

$$
\begin{aligned}
\tilde{X}_{t} & =\phi_{1} \tilde{X}_{t-1}+\phi_{2} \tilde{X}_{t-1}+\cdots+\phi_{p} \tilde{X}_{t-p}+Z_{t} \\
\tilde{X}_{t-h} \tilde{X}_{t} & =\phi_{1} \tilde{X}_{t-h} \tilde{X}_{t-1}+\phi_{2} \tilde{X}_{t-h} \tilde{X}_{t-1}+\cdots+\phi_{p} \tilde{X}_{t-h} \tilde{X}_{t-p}+\tilde{X}_{t-h} Z_{t}
\end{aligned}
$$

Selanjutnya dicari nilai harapan kedua ruas sehingga didapat:

$$
E\left[\tilde{X}_{t-h} \tilde{X}_{t}\right]=E\left[\phi_{1} \tilde{X}_{t-h} \tilde{X}_{t-1}+\phi_{2} \tilde{X}_{t-h} \tilde{X}_{t-1}+\cdots+\phi_{p} \tilde{X}_{t-h} \tilde{X}_{t-p}+\tilde{X}_{t-h} Z_{t}\right]
$$

Akibatnya diperoleh persamaan dari fungsi autokovariansi, dan setelah dibagi dengan $\gamma_{0}$ diperoleh persamaan $\rho_{h}=\phi_{1} \rho_{h-1}+\phi_{2} \rho_{h-2}+\cdots+\phi_{p} \rho_{h-p}$

Dengan mensubtitusikan $h=1,2, \ldots, p$, diperoleh

$$
\begin{gathered}
\rho_{1}=\phi_{1}+\phi_{2} \rho_{1}+\cdots+\phi_{p} \rho_{p-1} \\
\rho_{2}=\phi_{1} \rho_{1}+\phi_{2}+\cdots+\phi_{p} \rho_{p-2} \\
\cdots \\
\rho_{p}=\phi_{1} \rho_{p-1}+\phi_{2} \rho_{p-2}+\cdots+\phi_{p}
\end{gathered}
$$


Sehingga solusi dari estimasi $\phi_{1}, \phi_{2}, \ldots, \phi_{p}$ diperoleh dengan mensubstitusi fungsi autokorelasi sampel yaitu

$$
\left[\begin{array}{c}
\hat{\phi}_{1} \\
\hat{\phi}_{2} \\
\vdots \\
\hat{\phi}_{p}
\end{array}\right]=\left[\begin{array}{cccc}
1 & \hat{\rho}_{1} & \cdots & \hat{\rho}_{p-1} \\
\hat{\rho}_{1} & 1 & \cdots & \hat{\rho}_{p-2} \\
\vdots & \vdots & \ddots & \vdots \\
\hat{\rho}_{p-1} & \hat{\rho}_{p-2} & \cdots & 1
\end{array}\right]^{-1}\left[\begin{array}{c}
\hat{\rho}_{1} \\
\hat{\rho}_{2} \\
\vdots \\
\hat{\rho}_{p}
\end{array}\right]
$$

Berdasarkan sistem persamaan dapat diperoleh estimasi untuk model AR(p). Karena model AR(1) memiliki nilai $\mathrm{p}=1$ maka diperoleh $\hat{\phi}_{1}=\hat{\rho}_{1}$ dan karena model $\operatorname{AR}(2)$ memiliki nilai $\mathrm{p}=2$ maka diperoleh

$$
\left[\begin{array}{l}
\hat{\phi}_{1} \\
\hat{\phi}_{2}
\end{array}\right]=\left[\begin{array}{cc}
1 & \hat{\rho}_{1} \\
\hat{\rho}_{1} & 1
\end{array}\right]^{-1}\left[\begin{array}{l}
\hat{\rho}_{1} \\
\hat{\rho}_{2}
\end{array}\right]=\left[\begin{array}{c}
\frac{\hat{\rho}_{1}-\hat{\rho}_{1} \hat{\rho}_{2}}{1-\hat{\rho}_{1}{ }^{2}} \\
\frac{\hat{\rho}_{2}-\hat{\rho}_{1}{ }^{2}}{1-\hat{\rho}_{1}{ }^{2}}
\end{array}\right]
$$

dengan $\hat{\rho}_{h}=\frac{\widehat{\gamma}_{h}}{\widehat{\gamma}_{0}}=\frac{\sum_{t=0}^{n-1}\left(x_{t}-\bar{x}\right)\left(x_{t+1}-\bar{x}\right)}{\sum_{t=0}^{n}\left(x_{t}-\bar{x}\right)^{2}}$

\section{METODE MAKSIMUM LIKELIHOOD}

Misalkan $X_{1}, X_{2}, \ldots X_{n}$, adalah sampel acak dari suatu populasi yang berdistribusi Poisson dengan parameter $\lambda$. Fungsi kepadatan peluang untuk distribusi Poisson dengan parameter $\lambda$ adalah sebagai berikut

$$
f(x, \lambda)=\left\{\begin{array}{cl}
\frac{e^{-\lambda} \lambda^{x}}{x !}, & x=0,1,2, \ldots \\
0, & x \text { lainnya }
\end{array}\right.
$$

Estimator parameter $\lambda$ dengan metode Maksimum Likelihood adalah

$$
\hat{\lambda}=\frac{1}{n} \sum_{i=1}^{n} x_{i}
$$

MODEL INTEGER-VALUED AUTOREGRESSIVE ORDE SATU (INAR(1))

Misalkan X adalah variabel acak bilangan cacah, maka untuk setiap $\alpha \in[0,1]$ operasi o didefinisikan sebagai

$$
\alpha \circ X=\sum_{i=1}^{X} Y_{i}
$$

dengan $Y_{i}$ adalah variabel acak berdistribusi identik independen[3]. Nilai probabilitas $Y_{i}$ adalah

$$
P_{r}\left(Y_{i}=1\right)=1-P_{r}\left(Y_{i}=0\right)=\alpha
$$

Berdasarkan definisi o operasi maka jelas bahwa $0 \circ X=0,1 \circ X=X, E(\alpha \circ X)=\alpha E(X)$ dan untuk sembarang $\beta \in[0,1], \beta \circ(\alpha \circ X)=(\beta \alpha) \circ X$. Model INAR(1) digunakan untuk membangkitkan data deret waktu yang stationer dan berbentuk bilangan bulat. Model INAR(1) didefinisikan sebagai berikut $X_{t}=\alpha \circ X_{t-1}+\varepsilon_{t}$ dengan $\alpha \in[0,1]$ dan $\varepsilon_{t}$ merupakan variabel acak bernilai bilangan cacah yang memiliki rata-rata $\mu$ dan variansi berhingga $\sigma^{2}$. Variabel $\varepsilon_{t}$ adalah bilangan acak berdistribusi Poisson yang memiliki ciri i.i.d. (identically independent distributed) dengan $E\left[\varepsilon_{t}\right]=\mu$ dan $\operatorname{Var}\left[\varepsilon_{t}\right]=\mu$. Simbol $\circ$ menunjukkan binomial thinning operator, dimana $\alpha \circ X_{t-1}$ adalah nilai pada bilangan acak binomial dengan percobaan sebanyak $X_{t-1}$ kali dan $\alpha$ adalah peluang sukses pada setiap percobaan. Penurunan pada proses INAR adalah berdasar pada asumsi bahwa $\varepsilon_{t}$ bersifat i.i.d. distribusi Poisson, $\varepsilon_{t}$ $\sim$ Poisson $\left(\lambda_{t}\right)$ dimana $\lambda_{t}$ adalah rata-rata pada distribusi Poisson. Persamaan binomial thinning operator adalah sebagai berikut

$$
\alpha \circ X_{t-1}=Y_{1}+Y_{2}+\cdots+Y_{X_{t-1}}=\sum_{i=1}^{X_{t-1}} Y_{i}
$$


Dimana $Y_{i}$ merupakan deret dari variabel acak biner dengan sifat i.i.d. dan diberi nilai 1 dengan peluang $\alpha$ dan nilai 0 dengan peluang $1-\alpha$. Sehingga peluang pada masing-masing komponen $\mathrm{Y}$ yang sukses adalah $\alpha$ dan peluang gagal adalah $1-\alpha$.

\section{SIFAT-SIFAT STATISTIK INAR(1)}

Proses INAR(1) dapat dijabarkan sebagai berikut

$$
X_{t}=\alpha^{t} \circ X_{0}+\cdots+\alpha^{2} \circ \varepsilon_{t-2}+\alpha^{1} \circ \varepsilon_{t-1}+\alpha^{0} \circ \varepsilon_{t}
$$

Selanjutnya diperoleh sifat statistik yang pertama adalah rata-rata[3], yaitu

$$
\begin{aligned}
& E\left[X_{t}\right]=\alpha E\left[X_{t-1}\right]+\mu \\
& E\left[X_{t}\right]=\alpha^{t} E\left[X_{0}\right]+\cdots+\alpha^{2} \mu+\alpha^{1} \mu+\alpha^{0} \mu=\alpha^{t} E\left[X_{0}\right]+\mu \sum_{j=0}^{t-1} \alpha^{j}
\end{aligned}
$$

sifat selanjutnya adalah variansi[3], yaitu

$$
\operatorname{var}\left(X_{t}\right)=\alpha^{2} \operatorname{var}\left(X_{t-1}\right)+\alpha(1-\alpha) E\left[X_{t-1}\right]+\sigma^{2}
$$

karena $X_{t}$ stasioner pada rata-rata dan variansi maka diperoleh $E\left[X_{t}\right]=\frac{\mu}{1-\alpha}$ dan $\operatorname{var}\left(X_{t}\right)=\frac{\alpha \mu+\sigma^{2}}{1-\alpha^{2}}$.

Variansi untuk dua variabel dikenal dengan kovariansi. Kovariansi pada lag k dari model INAR(1) adalah

$$
\begin{aligned}
\gamma_{k} & =\operatorname{cov}\left(X_{t-k}, X_{t}\right)=\operatorname{cov}\left(X_{t-k}, \alpha^{k} \circ X_{t-k}\right)+\operatorname{cov}\left(X_{t-k}, \sum_{j=0}^{k-1} \alpha^{j} \circ \varepsilon_{t-j}\right) \\
& =\alpha^{k} \operatorname{var}\left(X_{t-k}\right)+\sum_{j=0}^{k-1} \alpha^{j} \operatorname{cov}\left(X_{t-k}, \varepsilon_{t-j}\right) \\
\gamma_{k} & =\alpha^{k} \gamma_{0} \\
\frac{\gamma_{k}}{\gamma_{0}} & =\alpha^{k}
\end{aligned}
$$

\section{ESTIMASI PARAMETER PROSES INAR(1)}

Prosedur estimasi pada proses INAR(1) digunakan untuk estimasi nilai parameter $\alpha$ dan $\lambda$ pada model INAR(1) yang diasumsikan bahwa variabel $\varepsilon_{t}$ yang bersifat i.i.d. mengikuti distribusi Poisson. Pada penelitian ini dibahas dua metode yaitu metode Yule-walker dan kuadrat terkecil bersyarat.

Metode Yule-walker merupakan metode estimasi yang menggunakan rumus momen ke k, sehingga untuk mengestimasi $\alpha$ menggunakan nilai korelasi sampel. Korelasi sampel dari model INAR(1) adalah seperti pada Persamaan (1) sehingga parameter $\alpha$ diestimasi sebagai:

$$
\hat{\alpha}=\frac{\sum_{t=0}^{n-1}\left(x_{t}-\bar{x}\right)\left(x_{t+1}-\bar{x}\right)}{\sum_{t=0}^{n}\left(x_{t}-\bar{x}\right)^{2}}
$$

Sedangkan nilai $\lambda$ karena merupakan parameter $\varepsilon_{t}$ yang berdistribusi Poisson maka dapat diestimasi berdasarkan persamaan (2) yaitu sebagai berikut:

$$
\hat{\lambda}=\frac{1}{n} \sum_{t=1}^{n} \varepsilon_{t}
$$

Metode kuadrat terkecil bersyarat adalah metode dengan meminimalkan nilai jumlah kuadrat data. Tidak seperti model AR(1) standar, untuk mencari estimasi model INAR(1) yang terdapat $X_{t-1}$ dan $\varepsilon_{t}$, dimana $X_{t}$ adalah variabel random acak. Rata-rata bersyarat dari $X_{t}$ oleh $X_{t-1}$ adalah

$$
E\left[X_{t} \mid X_{t-1}\right]=\alpha X_{t-1}+\lambda=g\left(\theta, X_{t-1}\right)
$$

dimana $\boldsymbol{\theta}=(\alpha, \lambda)$ adalah parameter yang akan diestimasi. 
Estimasi yang dilakukan dengan meminimalkan jumlah kuadrat sebagai syaratnya. Berdasarkan metode kuadrat terkecil estimasi untuk $\alpha$ dan $\lambda$ adalah nilai yang meminimalkan

$$
\begin{aligned}
Q_{n}(\boldsymbol{\theta}) & =\sum_{t=1}^{n}\left[X_{t}-g\left(\theta, X_{t-1}\right)\right]^{2} \\
& =\sum_{t=1}^{n}\left[X_{t}^{2}-2 X_{t} \alpha X_{t-1}-2 X_{t} \lambda+\alpha^{2} X_{t-1}^{2}+2 \alpha X_{t-1} \lambda+\lambda^{2}\right] .
\end{aligned}
$$

Persamaan (3) diturunkan terhadap $\alpha$ dan disamakan dengan 0 sehingga diperoleh

$$
\frac{\partial Q_{n}}{\partial \alpha}=\sum_{t=1}^{n}\left[-2 X_{t} X_{t-1}+2 \alpha X_{t-1}^{2}+2 X_{t-1} \lambda\right]=0
$$

selanjutnya Persamaan (3) diturunkan terhadap $\lambda$ dan disamakan dengan 0 sehingga diperoleh

$$
\frac{\partial Q_{n}}{\partial \lambda}=\sum_{t=1}^{n}\left[-2 X_{t}+2 \alpha X_{t-1}+2 \lambda\right]=0
$$

dengan eliminasi dan subtitusi diperoleh estimasi parameternya adalah $\hat{\alpha}=\frac{\sum_{t=0}^{n-1}\left(x_{t}-\bar{x}\right)\left(x_{t+1}-\bar{x}\right)}{\sum_{t=0}^{n}\left(x_{t}-\bar{x}\right)^{2}}$ dan $\hat{\lambda}=$ $\frac{1}{n} \sum_{t=1}^{n} \varepsilon_{t}$. Berdasarkan kestasioneran estimasi untuk rata-rata dan variansi untuk pengamatan ke-n akan sama dengan pengamatan ke-( $\mathrm{n}+1)$.

\section{KESIMPULAN}

Model INAR(1) adalah salah satu model yang digunakan untuk data diskrit. Sifat-sifat statistik yang dimiliki Model INAR(1) adalah rata-rata $E\left[X_{t}\right]=\frac{\mu}{1-\alpha}$ dan variansinya $\operatorname{var}\left(X_{t}\right)=\frac{\alpha \mu+\sigma^{2}}{1-\alpha^{2}}$. Karena model INAR(1) mempunyai dua variabel acak yaitu $X_{t}$ dan $\varepsilon_{t}$ maka parameter yng diestimasi adalah $\alpha$ dan $\lambda$. Parameter $\alpha$ merupakan parameter dari ditribusi $X_{t}$ sedangkan $\lambda$ merupakan parameter dari distribusi $\varepsilon_{t}$. Berdasarkan pembahasan tentang model INAR(1) maka diperoleh estimasi untuk parameter $\hat{\alpha}=$ $\frac{\sum_{t=0}^{n-1}\left(x_{t}-\bar{x}\right)\left(x_{t+1}-\bar{x}\right)}{\sum_{t=0}^{n}\left(x_{t}-\bar{x}\right)^{2}}$ dan $\hat{\lambda}=\sum_{t=1}^{n} \frac{\varepsilon_{t}}{n}$.

\section{DAFTAR PUSTAKA}

[1].Silva I., Silva M.E., Pereira I., Silva N. Replicated INAR(1) processes. Methodology and Computing in applied Probability. 2005; 7:517-542.

[2].Brännäs, Kurt. Estimation and Testing in Integer-valued AR(1) Models. Umeå Economic Studies 335. Umeå University; 1994.

[3].Al-Osh M.A., Alzaid A.A. First order integer-valued autoregressive (INAR(1)) processes. Journal of Time Series Analysis. 1987; 8:261-275.

[4].Gross D dan Haris C. M. Fundamental of Queueing Theory Ed ke-4. New Jersey: John Willey \& Sons; 2008.

[5].Wei,W.W. S. Time Series Analysis: Univariate and Multivariate Methods Ed ke-2. Boston: Pearson Addison Wesley; 2006.

[6].Hasan M.I. Pokok-pokok Materi Statistika 1. Jakarta: Bumi Aksara; 2001.

[7].Spiegel M.R., Stephens L.J. Teori dan Soal-Soal Statistik Ed ke-3. Jakarta: Erlangga; 2007.

[8].Hadi, S. Metodologi Research Jilid III. Yogyakarta: Andi Offset;2001.

[9].Spiegel M.R. Statistik : Belajar Super Cepat. Jakarta: Erlangga; 2004.

ALOYSIUS BILLY SAGA $\quad$ : Jurusan Matematika FMIPA UNTAN, Pontianak sagaaloysiusbilly@yahoo.com

YUNDARI

: Jurusan Matematika FMIPA UNTAN, Pontianak yundari@math.untan.ac.id

SHANTIKA MARTHA : : Jurusan Matematika FMIPA UNTAN, Pontianak shantika.martha@math.untan.ac.id 